\title{
The role of tumour markers and biomarkers in colorectal cancer
}

\author{
Minireview
}

\author{
G. LECH ${ }^{1, *}$, R. SLOTWINSKI ${ }^{2,3}$, I. W. KRASNODEBSKI ${ }^{1}$
}

${ }^{1}$ Department of General, Gastroenterological and Oncological Surgery, Medical University of Warsaw, Warsaw, Poland; ${ }^{2}$ Department of Surgical Research and Transplantology, Mossakowski Medical Research Centre, Polish Academy of Sciences, Warsaw, Poland; ${ }^{3}$ Department of Immunology, Biochemistry nad Nutrition, Medical University of Warsaw, Warsaw, Poland

*Correspondence: gustaw.lech@wum.edu.pl

Received February 17, 2013 / Accepted May 23, 2013

\begin{abstract}
A steady increase in colorectal cancer (CRC) incidence and mortality has been observed in Europe, despite the continuous advancement in diagnostic and therapeutic methods. Accordingly, further progress is very much desirable in non-invasive diagnostic methods to enable early diagnosis, pre- and postoperative staging, and to assist in selecting the most suitable neo-adjuvant and adjuvant therapeutic methods and post-treatment follow-up. This review summarizes the current state of knowledge about the role of tumor markers and biomarkers in CRC diagnosis, treatment and follow-up. New biomarkers which are absent in healthy persons and present in CRC are still being investigated, especially those that can be detected at early development stage of the disease and used in screening tests. Unfortunately, no molecule that would meet all of the foregoing criteria has been identified so far. Carcinoembryonic antigen still remains the only tumor marker of recognised efficacy in monitoring patients during and after CRC therapy. Clinical studies and retrospective analyses allowed to discover and introduce to the clinical practice several bioindicators that assist in selecting the proper chemotherapeutic drug. There are attempts to "personalise" chemotherapy based on presence or absence of specific biomarkers. Therapy with anti-EGFR antibodies is desirable in patients with advanced CRC and absence of KRAS or BRAF mutation. Defining tumor phenotype - microsatellite instability (MSI) or microsatellite stability (MSS) and testing for the presence or absence of 18q chromosome deletion is very much desirable in standard 5-FU-based therapy. Analysis of UGT1A1 alleles may be the basis for modified dosing and reducing the potential toxicity of irinotecan. Studies on CRC biomarkers need to continue to closely examine the relationship between therapy and CRC curability. Targeted therapy against membrane receptors appears to be the future of CRC therapy.
\end{abstract}

Key words: colorectal cancer, carcinoembryonic antigen CEA, microsatellite instability, chromosome 18q loss of heterozygosity, KRAS mutation, PIK3CA mutation, biomarker, tumour marker, tumor marker, colorectal cancer biomarkers

In 2010, colorectal cancer (CRC) was the third most common malignant cancer in both men and women in Europe [1]. There are 250,000 cases of colorectal cancer diagnosed on an annual basis in Europe only. Five-year survival was 54 percent among adult Europeans diagnosed with colorectal cancer between 1995 and 1999 [2]. A steady increase in colorectal cancer incidence and mortality has been observed, despite the continuous advancement in diagnostic and therapeutic methods. Accordingly, further progress is very much desirable in non-invasive diagnostic methods to enable early diagnosis, pre- and postoperative staging, and to assist in selecting the most suitable neo-adjuvant and adjuvant therapeutic methods and post-treatment follow-up. The concentrations of tumor markers tested at the diagnostic stage are believed to assist in cancer diagnosis, but are currently found to be more important during treatment and long-term follow-up.

The number of tumor markers used for tests continues to grow. Tumor markers are substances (most typically proteins, 
but also glycolipids) representing highly diversified biological structure, which can be attributed to the development of normal cells or carcinogenesis at different cell development stages. Tumor-associated antigens (TAAs), such as CEA, AFP, etc. are the largest group of clinically significant markers. TAAs are molecules produced by both, normal and neoplastic cells, but the amounts of TAAs produced by neoplastic cells are significantly higher. As a result, the concentration of TAAs typically correlates with the number (or mass) of specific neoplastic cells. Other types of markers are substances produced specifically by neoplastic cells through changes in genome, which are currently of no clinical significance, and substances produced by necrotizing cells.

In daily clinical practice, in the process of diagnosis and therapy, there are several parameters in use of long-established high sensitivity, specificity and positive predictive value. These parameters have been selected from among tens of molecules produced by cells in long-term laboratory tests, observational studies and clinical trials. New markers which are absent in healthy persons and present in specific tumors are still being investigated, especially those that can be detected at early development stage of the disease and used in screening tests. Unfortunately, no molecule that would meet all of the foregoing criteria has been identified so far. On the other hand, for some types of tumors, markers are also considered important in monitoring the progress of treatment, efficacy of neoadjuvant therapy, surgery, chemotherapy and adjuvant radiation therapy and follow-up for possible recurrence. Long-term observational studies also point to the fact that, apart from determining antigen concentration, it can be also important to trace its progress and dynamics. Low concentration dynamics can be indicative of local recurrence, whereas dynamically increasing levels may indicate the occurrence of distant metastases.

Tumor associated antigens. Carcinoembryonic antigen (CEA) was discovered almost 50 years ago, in 1965, and it still remains the only tumor marker of recognised efficacy in monitoring patients during and after CRC therapy [3]. CEA was first considered specific for CRC, but it was later discovered that elevated CEA levels (over $5.0 \mathrm{ng} / \mathrm{mL}$ for non-smokers and $10 \mathrm{ng} / \mathrm{mL}$ for smokers) can be also detected in cancer of the pancreas, stomach, bronchi, breast, bladder, genital organs, kidneys, in non-epithelial neoplasms, and in inflammatory conditions (chronic pancreatitis, liver cirrhosis). The usefulness of CEA tests in patients with colorectal cancer has been analysed in multiple studies based on large study populations. Plasma CEA concentration was found to represent poor sensitivity, however, CEA can be still used in screening tests for tumors [4]. In multiple studies, CEA levels were found to be elevated before surgery in ca. 50-60 percent of all patients with CRC stage I to IV, and the sensitivity of this parameter was observed to increase in parallel to CRC progression. Elevated CEA concentrations are only rarely identified in CRC stage I. Moreover, it does not differentiate benign versus malignant polyps. According to the 2003 EGTM Guidelines, confirmed by ASCO in $2006[5,6]$, CEA is not recommended for use in screening tests. On the other hand, no other marker of better sensitivity and specificity has been yet discovered for broadspectrum screening tests for CRC. Also in the 2010 ESMO Guidelines, elevated CEA levels are not listed as a prognostic factor [1]. In earlier studies, high CEA concentrations in patients with CRC stage II and III were found to be potentially indicative of more aggressive types of cancer $[7,8]$. In studies by Parka et al. on large populations of 2230 and 1146 patients, CEA concentration was considered a significant prognostic factor $[9,10]$. Based on these results, in 2000 the Colorectal Working Group of American Joint Committee on Cancer (AJCC) proposed to include CEA baseline concentration to the traditional TNM classification as the so-called C-stage. C-stage was proposed to be divided into $\mathrm{Cx}, \mathrm{C} 0(\mathrm{CEA}<5 \mathrm{ng} / \mathrm{mL})$ and $\mathrm{C} 1(\mathrm{CEA}>5 \mathrm{ng} / \mathrm{mL})$ substages [11]. The meaning of CEA as an independent prognostic factor was also confirmed in a recent retrospective analysis of 17910 patients with CRC, with a mean 27-month follow-up, with longer survival periods for patients with IIA C0 and IIIA C0 vs. I C1, IIIA C0 vs. IIA C1, and IIIB $\mathrm{C} 0$ vs. IIB-C C1, respectively [12]. From a prognostic point of view, it appears reasonable to determine CEA levels before surgery in patients with disseminated CRC. The roles of CEA in determining life expectancy was confirmed in several studies on patients with liver metastases [13,14]. CEA half-life is known to last app. 7 days. After R0 resection surgery, CEA levels should return to normal within 4 to 6 weeks. Sustained elevated CEA levels can be indicative of infiltration or metastases. Slow increase in CEA concentrations after surgery is a typical sign of local recurrence, whereas dynamically increasing levels can be symptomatic for metastases, most probably in the liver [15]. Testing CEA levels is considered most cost-effective in detecting post-surgery recurrences [16]. Please note that CEA levels tested every 3 months for the first 3 years and thereafter every 6 months for subsequent 2-3 years is a golden follow-up standard after CRC therapy recommended by a number of scientific associations (ASCO, ESMO) $[1,5,17]$. It appears particularly important in asymptomatic patients, in whom chemotherapy can be used, with a much longer life expectancy as compared to treatment administered after the onset of symptoms of recurrence. CEA is a marker of choice in monitoring disseminated disease during systemic therapy. Constant increase in CEA levels is typically associated with a progress of the disease, even though radiological tests may prove otherwise [5]. However, chemotherapy can also result in temporary increase in CEA concentration, which must be also taken into account. Therefore, it is not recommended to test CEA levels within 2 weeks from chemotherapy, whereas in patients on oxaliplatin, tests can be carried out after 4 to 6 weeks.

Cancer antigen 19-9 (CA 19-9) is a glycoprotein whose relevance in CRC diagnosis still remains an issue. The majority of researchers arrived at the conclusion that CA 19-9 sensitivity is much inferior to that of CEA, and that elevated CA 19-9 levels is a poor prognostic factor $[1,5,18,19,20]$. 
Table 1. Recommendations for use of tumour markers and biomarkers in colorectal cancer by groups of experts

\begin{tabular}{|c|c|c|c|c|}
\hline Biomarker & Applications & $\operatorname{ASCO}[5,68,69]$ & ESMO $[1,17]$ & NCCN [70] \\
\hline \multirow[t]{3}{*}{ CEA } & Screening & No & None published & None published \\
\hline & Prognostic factor & Yes & Yes & Yes \\
\hline & Follow up & Yes & Yes & Yes \\
\hline CA 19-9 & All & No & No & None published \\
\hline CA $72-4$ & All & None published & None published & None published \\
\hline CA 242 & All & None published & None published & None published \\
\hline MSI & Prognostic factor & No & Yes & Yes \\
\hline $18 \mathrm{qLOH}$ & Prognostic factor & Yes & Yes (potentially) & None published \\
\hline \multirow[t]{2}{*}{ KRAS } & Prognostic factor & None published & Yes (potentially) & None published \\
\hline & Predictive factor & Yes & Yes & Yes \\
\hline PIK3CA & Predictive factor & None published & Yes (potentially) & None published \\
\hline \multirow[t]{2}{*}{ BRAF } & Prognostic factor & None published & Yes & Yes \\
\hline & Predictive factor & Yes & Yes (potentially) & Yes (potentially) \\
\hline PTEN & Predictive factor & Yes (potentially) & Yes (potentially) & None published \\
\hline UGT1A1 & Predictive factor & Yes & Yes (only in case of severe toxicity of irinotecan) & No \\
\hline TPA, TPS & All & None published & None published & None published \\
\hline Ezrin & All & None published & None published & None published \\
\hline p53 gene & Prognostic factor & No & Yes (potentially) & None published \\
\hline DNA ploidy & All & No & None published & None published \\
\hline \multirow[t]{2}{*}{ TS } & Prognostic factor & No & Yes (potentially) & None published \\
\hline & Predictive factor & Yes (potentially) & Yes (potentially) & None published \\
\hline $\mathrm{TP}$ & All & No & None published & None published \\
\hline DPD & Predictive factor & No & Yes (only in case of severe toxicity of 5-FU) & None published \\
\hline$\beta-1,4-G T$ & All & None published & None published & None published \\
\hline
\end{tabular}

Cancer antigen 72-4 (CA 72-4) is a biomarker with poor sensitivity ranging from $9 \%$ to $31 \%$ and better specificity ranging from $89 \%$ to $95 \%$ in patients screened for CRC. The diagnostic information in recurrent CRC provided by CA 72-4 has borderline significance, by much worse than CEA. All authors conclude that CA 72-4 sensitivity is rather low and specifity incomplete in screening and following up in patients with CRC. On the other hand an algorithm based on combination of CEA, CA 19-9, CA 72-4, CA 242 improves the diagnostic accuracy compared with these biomarkers alone. $[18,19,20,21,22]$

Molecular biomarkers. With the recent progress in understanding the molecular mechanisms of cancer development, dissemination, resistance to chemotherapy and radiation therapy, it is now easier to select the most proper strategy for managing CRC. Clinical studies and retrospective analyses allowed to discover and introduce to the clinical practice several biomarkers that assist in selecting the proper chemotherapeutic agent, both standard agents, such as 5-fluorouracil, oxaliplatin or irinotecan, and new generation targeted drugs: cetuximab, bevacizumab or panitumumab. Biomarker identification is particularly important for patients with CRC stage II. In this group of patients, the risk of recurrence is only 20 percent. It is also desirable to use adjuvant therapy in this type of patients. There are attempts to select this group of patients based on genetic tests, or to "personalise" chemotherapy based on pres- ence or absence of specific biomarker. The following markers discovered throughout the recent years continue to be closely examined: microsatellite instability (MSI), chromosome $18 \mathrm{q}$ loss of heterozygosity $(18 \mathrm{qLOH})$, KRAS, BRAF, PTEN, PIK3CA mutations, and UGT1A1 gene polymorphism.

Microsatellite instability. Microsatellite instability (MSI) denotes changes in coding and non-coding sequences of microsatellite chromosomes, i.e. repeated DNA sequences. These sequences are particularly exposed to errors in the mutation repair system that consist in the loss or multiplication of nucleotide sequence repetitions, which results in shortening or extension of microsatellite regions in neoplastic cells. Mutations arising out of these processes are eliminated by mismatch repair genes (MMR), which makes some researchers believe that MSI can be caused by mutations in these genes [23,24]. Microsatellite instability can be classified into microsatellite instability-high (MSI-H) and microsatellite instability-low (MSI-L), depending on the percentage of loci that correlate to MSI characteristics. Tumor cells that lack MSI features are designated as MSS.

In retrospective studies and meta-analyses in patients with CRC stage II and III, MSI-H was shown to be a predictive factor that improved overall survival, irrespective of the progression (stage) of cancer. A lower incidence of lymph node metastases and distant metastases as compared to MSI-L or MSS cancer cells was also observed [25,26,27,28,29]. However, 
MSI should be considered more of a prognostic rather than predictive factor. This conclusion is based on equivocal results of studies evaluating the efficacy of 5-FU-based chemotherapy in groups of patients with MSI-H and MSI-L or MSS. Ribic et al. examined tumor specimens collected from 570 patients with CRC stage II and III and correlated the test results with chemotherapy outcomes in these patients to reveal a tendency for shorter overall survival in patients with MSI-H on adjuvant therapy. Significant improvement was observed in patients with MSS tumors [28]. A recent pooled analysis of randomized clinical studies revealed significant decrease in the overall fiveyear survival rate for patients with CRC stage II and MSI-H on 5-FU-based chemotherapy. 5-FU-based chemotherapy was found to improve therapeutic outcomes only in patients with CRC stage III and MSI-L or MSS [30]. Some studies indicated potentially negative effects of 5-FU-based chemotherapy in patients with MSI-H. A longer survival rate as compared to patients on 5-FU-based adjuvant chemotherapy was observed in a reference group of patients undergoing surgical treatment. Resistance of MSI-H tumors to 5-FU was also confirmed in in vitro studies [31,32]. A completely different conclusion can be drawn from earlier studies of Elsaleh et al., which confirmed the efficacy of 5-FU in patients with CRC stage III and MSI-H $[33,34,35]$. Beragnolli et al. revealed that a higher rate of overall 5-year progression-free survival was observed in patients with CRC stage III and MSI-H on 5-FU and irinotecan vs. 5-FU-based chemotherapy [36]. To recap, the results of MSI studies and clinical experience in patients with CRC stage II indicate that the degree of microsatellite instability may be of significance as a prognostic factor. Also, adjuvant 5-FU-based chemotherapy was proved to provide no benefits (or potentially cause adverse reactions) in patients with MSI-H. Therefore, high-risk patients should be rather administered irinotecanbased treatment. These findings have not been yet extended to oxalipatin-based therapy.

Chromosome 18q loss of heterozygosity. A number of studies were dedicated to another prognostic factor in patients with CRC stage II and III - chromosome 18q loss of heterozygosity in the coding place of, inter alia, SMAD 4 proteins specific to CRC. In these studies, the overall 5-year survival was poorer for patients with CRC stage III and $18 \mathrm{qLOH}$ as compared to non-18qLOH patients [37]. A meta-analysis of data from 27 studies and 2189 patients by Popat et al. confirmed that poorer survival was correlated with $18 \mathrm{q}$ chromosome deletion [38]. Two years later, the same research team questioned these findings after re-examining the same data [39]. Likewise, no correlation was identified between the presence of $18 \mathrm{qLOH}$ and 5 -year survival in patients with non-MSI-H phenotype [40]. The role of $18 \mathrm{qLOH}$ in predicting response to standard chemotherapy has not been yet fully confirmed. Watanabe et al. demonstrated better response to 5-FU-based chemotherapy in patients with CRC stage III and MSS and with the absence of $18 \mathrm{q}$ chromosome deletion vs. patients in whom $18 \mathrm{q}$ chromosome deletion was present [41]. The recently published results of the same research team can be a proof that in patients with CRC stage II and III and MSS-H (>33\%), the level of $\mathrm{LOH}$ of four chromosomes, including 18q, is correlated with significantly poorer survival rate as compared to patients with MSS and LOH-L or MSI-H phenotype [42].

Based on the available data, $18 \mathrm{q}$ chromosome deletion cannot be the sole basis for any therapeutic decisions, however, it is being more closely examined under ECOG 5202 study, featuring molecular markers identified so far in selecting the most proper adjuvant post-surgery treatment, by prospectively analysing the role of MSI and $18 \mathrm{qLOH}$ in prognosis and therapeutic decisions in patients with CRC stage II. Patients with good prognosis (with MSI-H and w/o 18qLOH) were followed-up, and patients with poor prognosis (with MSI-L or MSS and $18 \mathrm{qLOH}$ ) were randomized to one of two groups on chemotherapy (FOLFOX alone or FOLFOX and bevacizumab). No conclusion can be drawn from this study about the possible inefficacy of chemotherapy in patients with MSI-H, however, the study will include a multifactor analysis of biomarkers that can assist in taking therapeutic decisions in other groups of patients [43].

Biomarkers suitable in anti-EGFR therapy. A number of currently tested markers have been discovered in the course of studies on epidermal growth factor receptor (EGFR) signalling pathways. KRAS gene mutation on short arm of chromosome 12 at codon 12 (80\% of patients) or, to a lesser extent, codon 13 is believed to be of use as a biomarker in patients on cetuximab or panitumumab [44]. These mutations are one of the most common in proliferative diseases ( $37 \%$ and $13 \%$, respectively), and their significance in CRC carcinogenesis was examined in much detail $[45,46]$. As these mutations are present in EGFR signalling pathway, they can be a predictive factor for therapy with anti-EGFR antibodies. In studies performed so far, KRAS mutation was found to be correlated with non-responsiveness to cetuximab and panitumumab [47,48]. CRYSTAL and OPUS data indicate that the effectiveness of FOLFOX or FOLFIRI alone is no inferior to that of cetuximab in patients with KRAS in combination with chemotherapy according to FOLFIRI and FOLFOX regimen, respectively. However, in non-KRAS patients, cetuximab improves the therapeutic outcome $[49,50]$. The same conclusions can be drawn from the results of other large clinical studies: COIN, NORDIC VII or PRIME. However, the effects of KRAS mutation at codon 12 or 13 on tumor biology were found to differ. In two studies, the survival rate is higher in patients with an uncommon G13D mutation at codon 13 on cetuximab vs. patients with other mutations, and similar to patients with no KRAS mutations identified [44,51]. It is presently believed that anti-EGFR antigens should not be used in patients with tumors indicative of G12V mutation of KRAS at codon 12. For bevacizumab, KRAS mutation was found to be of no use as a predictive factor. The same applies to BRAF mutation found in 8-13 percent of patients with CRC, which makes the tumor to a large extent resistant to anti-EGFR monoclonal antibodies, and significantly worsens prognosis, especially in patients with MSI-L and MSS $[46,50,52,53]$. If the BRAF mutation is present, the overall survival period is 
slightly longer in patients on cetuximab [49]. Non-responsiveness to cetuximab and panitumumab has been also observed in patients with absence of phosphatase and tensin homologue deleted on chromosome ten (PTEN) expression [54].

PIK3CA mutations. Phosphatidylinositide-3-kinases (PI3K) are kinases that promote different biologic processes, including cellular proliferation. Mutation in the PIK3CA gene, which encodes the p110a catalytic subunit of PI3K have been identified in many human solid tumors, including CRC. The PIK3CA gene is mutated in $10-20 \%$ of CRC tumors. The PIK3CA gene encode the kinase that regulates, alongside with KRAS, downstream signalling pathways of the EGFR. The p110a catalytic subunit of PI3K may be activated by interaction with RAS proteins. Moreover, PI3K-initiated signalling is inhibited by PTEN. Recent studies have found that compared with patients with PIK3CA wild-type tumors, those with PIK3CA-mutated tumors experienced an increase in colon cancer-specific mortality $[55,56]$. Although, the researchers report that only coexistence of PIK3CA exon 9 and 20 mutations but not PIK3CA mutation in either exon 9 or 20 alone may be associated with worse prognosis [56]. Among patients with KRAS wild-type tumors, the presence of PIK3CA mutation was associated with a significant increase in colon cancerspecific mortality. In contrast, PIK3CA mutation conferred no significant effect on mortality among patients with KRASmutated tumors. Thus, the effect of PIK3CA mutation may be potentially limited to patients with KRAS wild-type tumors [55]. Following the fact that only patients with KRAS-wild type CRC may respond to anti-EGFR antibodies several studies investigate the role of PIK3CA mutations on CRC cells response to cetuximab or panitumumab. So far collected data indicate that CRC with PIK3CA mutations are significantly resistant to anti-EGFR antibodies. When only KRAS wild-type tumors are analyzed, the correlation is even stronger $[57,58,59]$. Recent studies have found that inhibition of cyclooxygenase- 2 by regular use of aspirin after CRC diagnosis was associated with longer cancer specific survival among patients with mutated PIK3CA in contrast to patients with wild-type PIK3CA. The authors conclude that the PIK3CA mutations may serve as predictive biomarker for adjuvant aspirin therapy [60]. Further studies involving KRAS mutated CRC patients are necessary to establish the role of aspirin in PI3K pathway.

Biomarker of the potential toxicity of irinotecan. Irinotecan is a chemotherapeutic agent that inhibits topoisomerase I, thereby inhibiting replication and stimulating cell apoptosis. Advanced neutropenia and intensive diarrhoea caused by damaged intestinal epithelium are the most common adverse effects of irinotecan, which significantly limit its use. UGT1A1 gene polymorphism is a very useful biomarker of the potential toxicity of irinotecan. It appears that the use of genetic tests is reasonable before treatment initiation with irinotecan to avoid severe adverse effects - mainly neutropenia in women. Genotyping for UGT1A1 can be carried out to select a group of sensitive patients with UGT1A $1^{\star} 28$ allele, of whom lower initial doses would be recommended. Hopefully, it will also allow to administer a higher accumulated dose of the drug, divided into smaller portions, to limit its toxicity [61]. However, according to a recent meta-analysis, genotyping for UGT1A1 has no predictive value in terms of responsiveness to various doses of irinotecan among patients with CRC [62]. On the other is recommended by ESMO for patients with several toxicity reaction in whom irinotecan in high doses should be used [17].

Other biomarkers. Tissue polypeptide antigen (TPA) and tissue polypeptide-specific antigen (TPS) which detects the fragments of cytokeratines 8,18 and 19 due to lack of sensitivity and specificity can not to be recommended in CRC screening. The majority of investigators have found that increased levels of TPA and TPS are observed in metastatic stage of CRC. A further studies has suggested that combination of TPA and CEA rises the sensitivity of these biomarkers in identifying the patients with CRC recurrence $[18,21,63,64]$.

Ezrin protein, a part of ezrin/radixin/moesin (ERM) family, which act as linkers between the plasma membrane and cytoskeleton, may play an important role in the process of tumor invasion. Recent studies has found that overexpression of ezrin protein correlates with CRC aggressiveness, its metastatic potential and worse prognosis. High ezrin expression was also identified as marker of early local recurrence of rectal cancer $[65,66]$. Although further investigation is needed, ezrin may represent a relevant biomarker and target for personalized anti-metastatic therapies.

Tumor beta-1,4-galactosyltransferase $(\beta-1,4-\mathrm{GT})$ expression level is apparently enhanced during tumorgenesis, but significantly overexpressed only in patients with tumor metastases and poor prognosis [67]. Thymidine synthethase (TS), dihydropyrimidine dehydrogenase (DPD) and p53 gene mutations may serve as potential prognostic and predictive factors in CRC [17]. Other biomarkers, such as: thymidine phosphorylase (TP), DNA ploidy were determined to be insignificant in detecting, staging and following-up of patients with CRC [5].

Conclusions. To recap, CEA levels - along with other laboratory tests and diagnostic imaging - can be considered an important follow-up factor in patients with CRC, which was already recognised in the guidelines of international cancer associations. Approximately 20 percent of patients with CRC recurrence are known to have normal plasma CEA levels in peripheral blood. In this patient group, it seems reasonable to search for other tumor markers or prognostic factors. No other marker of better sensitivity and specificity has been yet discovered to be used in broad-spectrum screening tests for CRC. The recent studies in this area result in a better understanding of colorectal cancer and assist in the development of new treatment regimens, especially in advanced CRC stages. The new predictive factors, molecular imaging, or even commercial genome tests increasingly facilitate tumor genome testing and assist in selecting targeted therapies. Therapy with anti-EGFR antibodies is desirable in patients with advanced CRC and absence of KRAS or BRAF mutation. Defining 
tumor phenotype (MSI/MSS) and testing for the presence or absence of $18 \mathrm{q}$ chromosome deletion is very much desirable in standard 5-FU-based therapy. Analysis of UGT1A1 alleles can be the basis for modified dosing and reducing the potential toxicity of irinotecan. Studies on CRC bioindicators need to continue to closely examine the relationship between therapy and CRC curability. Targeted therapy against membrane receptors appears to be the future of CRC therapy. Some promising studies are now carried out in this area, dedicated to, inter alia, other EGFR, insulin-like growth factor (IGF), platelet-derived growth factor receptor (PDGFR) and c-MET inhibitors, as well as receptors of tumor necrosis factor-related apoptosisinducing ligand (TRAIL).

\section{References}

[1] LABIANCA R, NORDLINGER B, BERETTA GD, BRONQUET A, CERVANTES A. Primary colon cancer: ESMO Clinical Practice Guidelines for diagnosis, adjuvant treatment and follow-up. Ann Oncol 2010; 21: 70-77. http://dx.doi. org/10.1093/annonc/mdq168

[2] BERRINO F, DE ANGELIS R, SANT M, ROSSO S, BIELSKALASOTA $M$ et al. Survival for eight major cancers and all cancers combined for European adults diagnosed in 1995-99: results of the EUROCARE-4 study. Lancet Oncol 2007; 8: 773-783. http://dx.doi.org/10.1016/S1470-2045(07)70245-0

[3] GOLD P, FREEDMAN SO. Demonstration of tumor specific antigens in human colonic carcinoma by immunological tolerance and absorption techniques. J Exp Med 1965; 121: 439-462. http://dx.doi.org/10.1084/jem.121.3.439

[4] PALMQVIST R, ERGARAS B, LINDMARK G, HALLMANS G, TAVELIN B et al. Prediagnostic levels of carcinoembryonic antigen and CA 242 in colorectal cancer: A matched case-control study. Dis Colon Rectum 2003; 46: 538-544. http://dx.doi. org/10.1007/s10350-004-6810-Z

[5] LOCKER GY, HAMILTON S, HARRIS J, JESSUP JM, KEMENY N et al. American Society of Clinical Oncology 2006 Update of Recommendations for the Use of Tumor Markers in Gastrointestinal Cancer. J Clin Oncol 2006; 24: 5313-5327. http://dx.doi.org/10.1200/JCO.2006.08.2644

[6] DUFFY MJ, VAN DALEN A, HAGLUND C, HANSSON L, KLAPDOR R et al. Clinical utility of biochemical markers in colorectal cancer: European Group on Tumor Markers (EGTM) guidelines. Eur J Cancer 2003; 39: 718-727. http:// dx.doi.org/10.1016/S0959-8049(02)00811-0

[7] CHEN CC, YANG SH, LIN JK, LIN TC, CHEN WS et al. Is it reasonable to add preoperative serum level of CEA and CA 19-9 to staging for colorectal cancer? J Surg Res 2005; 124: 369-374.

[8] WEISSENBERGER C, VON PLEHN G, OTTO F, BARKE A, MOMM F et al. Adjuvant radiochemotherapy of stage II and III rectal adenocarcinoma: Role of CEA and CA 19-9. Anticancer Res 2005; 25: 1787-1793.

[9] PARK YJ, YOUK EG, CHOI HS, HAN SU, PARK KJ et al. Experience of 1446 rectal cancer patients in Korea and analysis of prognostic factors. Int J Colorectal Dis 1999; 14: 101-106. http://dx.doi.org/10.1007/s003840050193
[10] PARK YJ, PARK KJ, PARK JG, LEE KU, CHOE KJ et al. Prognostic factors in 2230 Korean colorectal cancer patients: Analysis of consecutively operated cases. World J Surg 1999; 23: 721-726. http://dx.doi.org/10.1007/PL00012376

[11] COMPTON C, FENOGLIO-PREISER CM, PETTIGREWN, FIELDING LP. American Joint Committee on Cancer Prognostic Factors Consensus Conference: Colorectal Working Group. Cancer 2000; 8: 1739-1757. http://dx.doi. org/10.1002/(SICI) 1097-0142(20000401)88:7<1739::AIDCNCR30>3.0.CO;2-T

[12] THIRUNAVUKARASU P, SUKUMAR S, SATHAIAH M, MAHAN M, PRAGATHEESHWAR KD et al. C-stage in colon cancer: implications of carcinoembryonic antigen biomarker in staging, prognosis, and management. J Natl Cancer Inst 2011; 103: 689-697. http://dx.doi.org/10.1093/jnci/djr078

[13] UENO H, MOCHIZUKI H, HATSUSE K, HASE K, YAMAMOTO T. Indicators for treatment strategies of colorectal liver metastases. Ann Surg 2000; 231: 59-66. http://dx.doi. org/10.1097/00000658-200001000-00009

[14] MALA T, BOHLER G, MATHISEN O, BERGAN A, SOREIDE O. Hepatic resection for colorectal metastases: Can preoperative scoring predict patient outcome? World J Surg 2002; 26: 1348-1353. http://dx.doi.org/10.1007/s00268-002-6231-x

[15] GOLDSTEIN MJ, MITCHELL EP. Carcinoembryonic antigen in the staging and follow-up of patients with colorectal cancer. Cancer Invest 2005; 23: 338-351. http://dx.doi.org/10.1081/ CNV-58878

[16] GRAHAM RA, WANG S, CATALANO PJ, HALLER DG. Postsurgical surveillance of colon cancer: preliminary cost analysis of physician examination, carcinoembryonic antigen testing, chest x-ray, and colonoscopy. Ann Surg 1998; 228: 59-63. http://dx.doi.org/10.1097/00000658-199807000-00009

[17] SCHMOLL HJ, VAN CUTSEM E, STEIN A, VALENTINI V, GLIMELIUS B et al. ESMO Consensus Guidelines for management of patients with colon and rectal cancer. A personalized approach to clinical decision making. Ann Onc 2012; 23: 2479-2516. http://dx.doi.org/10.1093/annonc/mds236

[18] NICOLINI A, FERRARI P, DUFFY MJ, ANTONELLI A, ROSSI G et al. Intensive risk-adjusted follow-up with the CEA, TPA, CA19.9, and CA72.4 tumor marker panel and abdominal ultrasonography to diagnose operable colorectal cancer recurrences. Effect on survival. Arch Surg 2010; 145: 1177-1183. http://dx.doi.org/10.1001/archsurg.2010.251

[19] CARPELAN-HOLMSTROM M, LOUHIMO J, STENMAN UH, ALFTHAN H, JARVINEN H et al. CEA, CA 242, CA 19-9, CA 72-4 and hCGbeta in the diagnosis of recurrent colorectal cancer. Tumor Biol 2004; 25: 228-234. http://dx.doi. org $/ 10.1159 / 000081385$

[20] LUMACHI F, MARINO F, ORLANDO R, CHIARA GB, BASSO SM. Simultaneous multianalyte immunoassay measurement of five serum tumor markers in the detection of colorectal cancer. Anticancer Res 2012; 32: 985-988.

[21] LEVY M, VISOKAI V, LIPSKA L, TOPOLCAN O. Tumor markers in staging and prognosis of colorectal carcinoma. Neoplasma 2008; 55: 138-142.

[22] MARRELLI D, CARUSO S, NERI A, PEDRAZZANI C, CAPUANO L et al. Clinical utility of serum tumor markers in 
the diagnosis of malignant intestinal occlusion. A prospective observational study. Int J Biol Markers 2011; 26: 58-64. http:// dx.doi.org/10.5301/JBM.2011.6284

[23] BABA Y, NOSHO K, SHIMA K, IRAHARA N, KURE S et al. Aurora-A expression is independently associated with chromosomal instability in colorectal cancer. Neoplasia 2009; 11: 418-425.

[24] BOLAND CR, THIBODEAU SN, HAMILTON SR, SIDRANSKY D, ESHLEMAN JR et al. A National Cancer Institute Workshop on Microsatellite Instability for cancer detection and familial predisposition: development of international criteria for the determination of microsatellite instability in colorectal cancer. Cancer Res 1998; 58: 5248-5257.

[25] POPAT S, HUBNER R, HOULSTON RS. Systematic review of microsatellite instability and colorectal cancer prognosis. J Clin Oncol 2005; 23: 609-618. http://dx.doi.org/10.1200/ LCO.2005.01.086

[26] GRYFE R, KIM H, HSIEH ET, ARONSON MD, HOLOWATY EJ et al. Tumor microsatellite instability and clinical outcome in young patients with colorectal cancer. N Engl J Med 2000; 342: 69-77. http://dx.doi.org/10.1056/NEJM200001133420201

[27] SAMOWITZ WS, CURTIN K, MA KN, SCHAFFER D, COLEMAN LW et al. Microsatellite instability in sporadic colon cancer is associated with an improved prognosis at the population level. Cancer Epidemiol Biomarkers Prev 2001; 10: 917-923.

[28] RIBIC CM, SARGENT DJ, MOORE MJ, THIBODEAU SN, FRENCH AJ et al. Tumor microsatellite-instability status as a predictor of benefit from fluorouracil-based adjuvant chemotherapy for colon cancer. N Engl J Med 2003; 349; 247-257. http://dx.doi.org/10.1056/NEJMoa022289

[29] KIM GP, COLANGELO LH, WIEAND HS, PAIK S, KIR$\mathrm{SCH}$ IR et al. Prognostic and predictive roles of high-degree microsatellite instability in colon cancer: a National Cancer Institute-National Surgical Adjuvant Breast and Bowel Project Collaborative Study. J Clin Oncol 2007; 25: 767-772. http:// dx.doi.org/10.1200/JCO.2006.05.8172

[30] SINICROPE FA, SARGENT DJ. Clinical implications of microsatellite instability in sporadic colon cancers. Curr Opin Oncol 2009; 21: 369-373. http://dx.doi.org/10.1097/ CCO.0b013e32832c94bd

[31] MEYERS M, WAGNER MW, HWANG HS, KINSELLA TJ, BOOTHMAN DA. Role of the hMLH1 DNA mismatch repair protein in fluoropyrimidine-mediated cell death and cell cycle responses. Cancer Res 2001; 61: 5193-5201.

[32] CARETHERS JM, CHAUHAN DP, FINK D, NEBEL S, BRESALIER RS et al. Mismatch repair proficiency and in vitro response to 5-fluorouracil." Gastroenterology 1999; 117: 123-131. http://dx.doi.org/10.1016/S0016-5085(99)70558-5

[33] ELSALEH H, IACOPETTA B. Microsatellite instability is a predictive marker for survival benefit from adjuvant chemotherapy in a population-based series of stage III colorectal carcinoma. Clin Colorectal Cancer 2001; 1: 104-109. http:// dx.doi.org/10.3816/CCC.2001.n.010

[34] ELSALEH H, POWELL B, MCCAUL K, GRIEU F, GRANT R et al. $\mathrm{P} 53$ alteration and microsatellite instability have predictive value for survival benefit from chemotherapy in stage III colorectal carcinoma. Clin Cancer Res 2001; 7: 1343-1349.
[35] ELSALEH H, JOSEPH D, GRIEU F, ZEPS N, SPRY N et al. Association of tumor site and sex with survival benefit from adjuvant chemotherapy in colorectal cancer. Lancet 2000; 355 : 1745-1750. http://dx.doi.org/10.1016/S0140-6736(00)02261$\underline{3}$

[36] BERTAGNOLLI MM, NIEDZWIECKI D, COMPTON CC, HAHN HP, HALL M et al. Microsatellite instability predicts improved response to adjuvant therapy with irinotecan, fluorouracil, and leucovorin in stage III colon cancer: Cancer and Leukemia Group B Protocol 89803. J Clin Oncol 2009; 27: 1814-1821. http://dx.doi.org/10.1200/JCO.2008.18.2071

[37] SARLI L, BOTTARELLI L, BADER G, IUSCO D, PIZZI S et al. Association between recurrence of sporadic colorectal cancer, high level of microsatellite instability, and loss of heterozygosity at chromosome 18q. Dis Colon Rectum 2004; 47: 1467-1482. http://dx.doi.org/10.1007/s10350-004-0628-6

[38] POPAT S, HOULSTON RS. A systematic review and metaanalysis of the relationship between chromosome $18 \mathrm{q}$ genotype, DCC status and colorectal cancer prognosis. Eur J Cancer 2005; 41: 2060-2070. http://dx.doi.org/10.1016/ j.ejca.2005.04.039

[39] POPAT S, ZHAO D, CHEN Z, PAN H, SHAO Y et al. Relationship between chromosome $18 \mathrm{q}$ status and colorectal cancer prognosis: a prospective, blinded analysis of 280 patients. Anticancer Res 2007; 27: 627-633.

[40] OGINO S, NOSHO K, IRAHARA N, SHIMA K, BABA Y et al. Prognostic significance and molecular associations of 18q loss of heterozygosity: A cohort study of microsatellite stable colorectal cancers. J Clin Oncol 2009; 27: 4591-4598. http://dx.doi.org/10.1200/JCO.2009.22.8858

[41] WATANABE T, WU TT, CATALANO PJ, UEKI T, SATRIANO $R$ et al. Molecular predictors of survival after adjuvant chemotherapy for colon cancer. N Engl J Med 2001; 344: 1196-1206. http://dx.doi.org/10.1056/NEJM200104193441603

[42] WATANABE T, KOBUNAI T, YAMAMOTO Y, MATSUDA K, ISHIHARA S et al. Chromosomal instability (CIN) phenotype, CIN high or CIN low, predicts survival for colorectal cancer. J Clin Oncol 2012; 30: 2256-2264. http://dx.doi.org/10.1200/ LCO.2011.38.6490

[43] http://clinicaltrials.gov/ct2/show/study/NCT00217737?term $=\mathrm{ecog}+5202 \& \mathrm{rank}=1$

[44] DE ROOCK W, JONKER DJ, DI NICOLANTONIO F, SARTORE-BIANCHI A, TU D et al. Association of KRAS p.G13D mutation with outcome in patients with chemotherapy-refractory metastatic colorectal cancer treated with cetuximab. JAMA 2010; 304: 1812-1820. http://dx.doi.org/10.1001/ jama.2010.1535

[45] SALAHSHOR S, KRESSNER U, PAHLMAN L, GLIMELIUS B, LINDMARK G et al. Colorectal cancer with and without microsatellite instability involves different genes. Genes Chromosomes Cancer 1999; 26: 247-252. http://dx.doi. org/10.1002/(SICI)1098-2264(199911)26:3<247::AIDGCC9>3.0.CO;2-H

[46] MARKOWITZ SD, BERTAGNOLLI MM. Molecular origins of cancer: Molecular basis of colorectal cancer. N Engl J Med 2009; 361: 2449-2460. http://dx.doi.org/10.1056/ $\underline{\text { NEJMra0804588 }}$ 
[47] DIFIORE F, BLANCHARD F, CHARBONNIER F, LE PESSOT F, LAMY A et al. Clinical relevance of KRAS mutation detection in metastatic colorectal cancer treated by Cetuximab plus chemotherapy. Br J Cancer 2007; 96: 1166-1169. http://dx.doi. org/10.1038/sj.bjc. 6603685

[48] LIEVRE A, BACHET JB, BOIGE V, CAYRE A, LE CORRE $\mathrm{D}$ et al. KRAS mutations as an independent prognostic factor in patients with advanced colorectal cancer treated with cetuximab. J Clin Oncol 2008; 26: 374-379. http://dx.doi. org/10.1200/JCO.2007.12.5906

[49] VAN CUTSEM E, KOHNE CH, LANG I, FOLPRECHT G, NOWACKI MP et al. Cetuximab plus irinotecan, fluorouracil, and leucovorin as first-line treatment for metastatic colorectal cancer: updated analysis of overall survival according to tumor KRAS and BRAF mutation status. J Clin Oncol 2011; 29: 2011-2019. http://dx.doi.org/10.1200/JCO.2010.33.5091

[50] BOKEMEYER C, CUTSEM EV, ROUGIER P, CIARDIELLO F, HEEGER $S$ et al. Addition of cetuximab to chemotherapy as first-line treatment for KRAS wild-type metastatic colorectal cancer: pooled analysis of the CRYSTAL and OPUS randomised clinical trials. Eur J Cancer 2012; 48; 1466-1475. http://dx.doi.org/10.1016/j.ejca.2012.02.057

[51] TEJPAR S, CELIK I, SCHLICHTING M, SARTORIUS U, BOKEMEYER C et al. Association of KRAS G13d tumor mutations with outcome in patients with metastatic colorectal cancer treated with first-line chemotherapy with or without cetuximab. J Clin Oncol 2012; 30: 3570-3577. http://dx.doi. org/10.1200/JCO.2012.42.2592

[52] DI NICOLANTONIO F, MARTINI M, MOLINARI F, SARTORE-BIANCHI A, ARENA $S$ et al. Wild-type BRAF is required for response to panitumumab or cetuximab in metastatic colorectal cancer. J Clin Oncol 2008; 26: 5705-5712. http://dx.doi.org/10.1200/JCO.2008.18.0786

[53] ROTH AD, TEJPAR S, DELORENZI M, YAN P, FIOCCA $\mathrm{R}$ et al. Prognostic role of KRAS and BRAF in stage II and III resected colon cancer: results of the translational study on the PETACC-3, EORTC 40993, SAKK 60-00 trial. J Clin Oncol 2010; 28: 466-474. http://dx.doi.org/10.1200/ LCO.2009.23.3452

[54] SOOD A, MCCLAIN D, MAITRA R, BASU-MALLICK A, SEETHARAM R et al. PTEN gene expression and mutations in the PIK3CA gene as predictors of clinical benefit to anti-epidermal growth factor receptor antibody therapy in patients with KRAS wild-type metastatic colorectal cancer. Clin Colorectal Cancer 2012; 11: 143-150. http://dx.doi. org/10.1016/j.clcc.2011.12.001

[55] OGINO S, NOSHO K, KIRKNER GJ, SHIMA K, IRAHARA $\mathrm{N}$ et al. PIK3CA mutation is associated with poor prognosis among patients with curatively resected colon cancer. 2009; 27: $1477-1484$.

[56] LIAO X, MORIKAWA T, LOCHHEAD P, IMAMURA Y, KUCHIBA A et al. Prognostic role of PIK3CA mutation in colorectal cancer: cohort study and literature review. Clin Cancer Res 2012; 18: 2257-2268. http://dx.doi.org/10.1158/ 1078-0432.CCR-11-2410

[57] JHAWER M, GOEL S, WILSON A J, MONTAGNA C, LING YH et al. PIK3CA mutation/PTEN expression status predicts response of colon cancer cells to the epidermal growth factor receptor inhibitor cetuximab. Cancer Res 2008; 68: 1953-1961. http://dx.doi.org/10.1158/0008-5472.CAN-07-5659

[58] SARTORE-BIANCHI A, MARTINI M, MOLINARI F, VERONESE S, NICHELATTI $M$ et al. PIK3CA mutations in colorectal cancer are associated with clinical resistance to EGFRtargeted monoclonal antibodies. Cancer Res 2009; 69: 1851-1857. http://dx.doi.org/10.1158/0008-5472.CAN-08-2466

[59] DEROOCK W, CLAES B, BERNASCONI D, DE SCHUTTER J, BIESMANS B et al. Effects of KRAS, BRAF, NRAS, and PIK3CA mutations on the efficacy of cetuximab plus chemotherapy in chemotherapy-refractory metastatic colorectal cancer: a retrospective consortium analysis. Lancet Oncol 2010; 11: 753-762. http://dx.doi.org/10.1016/S1470-2045(10)70130-3

[60] LIAO X, LOCHHEAD P, NISHIHARA R, MORIKAWA T, KUCHIBA A et al. Aspirin use, tumor PIK3CA mutation, and colorectal-cancer survival. N Engl J Med 2012; 367: 1596-1606. http://dx.doi.org/10.1056/NEJMoa1207756

[61] SHULMAN K, COHEN I, BARNETT-GRINESS O, KUTEN A, GRUBER SB et al. Clinical implications of UGT1A1*28 genotype testing in colorectal cancer patients. Cancer 2011; 117: 3156-3162. http://dx.doi.org/10.1002/cncr.25735

[62] DIAS MM, MCKINNON RA, SORICH MJ. Impact of the UGT1A $1 * 28$ allele on response to irinotecan: a systematic review and meta-analysis. Pharmacogenomics 2012; 13: 889-899. http://dx.doi.org/10.2217/pgs.12.68

[63] BYSTROM P, BERGLUND A, NYGREN P, WERNROTH L, JOHANSSON B et al. Evaluation of predictive markers for patients with advanced colorectal cancer. Acta Oncol 2012; 51: 849-859. http://dx.doi.org/10.3109/0284186X.2012.705020

[64] HOLDENRIEDER S, STIEBER P, LISKA V, TRESKA V, TOPOLCAN O et al. Cytokeratin serum biomarkers in patients with colorectal cancer. Anticancer Res 2012; 32: 1971-1976.

[65] PATARA M, MONTEIRO SANTOS EM, DE ALMEIDA COUDRY R, SOARES FA, FERREIRA FO et al. Ezrin expression as a prognostic marker in colorectal adenocarcinoma. Pathol Oncol Res 2011; 17: 827-833. http://dx.doi. org/10.1007/s12253-011-9389-4

[66] JORGREN F, NILBERT M, RAMBECH E, BENDAHL PO, LINDMARK G. Ezrin expression in recital cancer predicts time to development of local recurrence. Int J Colorectal Dis 2012; 27: 893-899. http://dx.doi.org/10.1007/s00384-011-1397-z

[67] CHEN WS, CHANG HY, LI CP, LIU JM, HUANG TS. Tumor $\beta$-1,4-galactosyltransferaze iv overexpression is closely associated with colorectal cancer metastasis and poor prognosis. Clin Cancer Res 2005; 11: 8615-8622. http://dx.doi. org/10.1158/1078-0432.CCR-05-1006

[68] LENZ HJ. Established biomarkers for colon cancer. In: American Society of Clinical Oncology 2009 Educational Book. ASCO, 2009: 215-219.

[69] ELLIS LM. Promising future biomarkers for colorectal cancer. In: American Society of Clinical Oncology 2009 Educational Book. ASCO, 2009: 212-214.

[70] ENGSTROM PF, ARNOLETTI JP, BENSON AB, CHEN YI, CHOTI MA et al. Colon Cancer Clinical practice guidelines in oncology. JNCCN 2009; 7: 778-831. 